\title{
PENGARUH KOMPETENSI GURU RUMPUN IPS TERHADAP WORD OF MOUTH POSITIF SISWA SEKOLAH MENENGAH ATAS MUHAMMADIYAH 1 PEKANBARU
}

\author{
Oleh : Hendra Riofita \& Nike Fitria \\ Universitas Islam Negeri Sultan Syarif Kasim Riau \\ hendrariofita@yahoo.com, nikefitria@gmail.com
}

\begin{abstract}
Abstrak
Tujuan dari penelitian ini adalah untuk mengetahui pengaruh kompetensi guru terhadap word of mouth positif siswa di Sekolah Menegah Muhammadiyah 1 Pekanbaru. Populasi penelitian adalah seluruh siswa yang belajar IPS di Sekolah tersebut yang berjumlah sebanyak 660 orang dengan sampel siswa kelas XI IPS yang berjumlah 82 orang dan diambil secara Stratified Purposive Random Sampling. Data diambil dengan menggunakan angket dan setelah dilakukan uji asumsi klasik, dianalisa dengan regresi linear berganda. Hasil penelitian menunjukkan bahwa: kompetensi pedagogik guru rumpun IPS secara statistic mempengaruhi secara signifikan terhadap variabel dependen word of mouth positif siswa, kompetensi kepribadian guru rumpun IPS secara statistic mempengaruhi secara signifikan terhadap variabel dependen word of mouth positif siswa, variabel kompetensi sosial guru rumpun IPS secara statistik mempengaruhi secara signifikan terhadap variabel dependen word of mouth positif siswa, kompetensi professional guru IPS mempengaruhi variabel dependen word of mouth positif dan kompetensi guru IPS secara bersama-sama
\end{abstract} mempengaruhi variabel dependen word of mouth positif.

Kata Kunci: Kompetensi Guru, Word of Mouth

\begin{abstract}
The objective of this research was to find the effect of teachers competencies toward students' positive words of mouth at Sekolah Menengah Atas Muhammadiyah 1 Pekanbaru. The population were all students studying IPS namely 660 students and samples were 82 students at class XI IPS taken by Stratified Purposive Random Sampling technique. Data were taken by using quistionaire and after treated by classic assumption test, the data were analyzed by multiple linear analysis. The result showed that statistically, pedhagogy competency of IPS teachers influenced students' posititive words of mouth significantly, Personality competency of IPS teachers statistically influenced students' posititive words of mouth significantly, Social competency of IPS teachers statistically influenced students' posititive words of mouth significantly, Professional competency of IPS teachers statistically influenced students' posititive words of mouth significantly and together IPS teachers competency influenced students' positive words of mouth.
\end{abstract}

Key Words: Teacher Competency, Words of Mouth 


\section{PENDAHULUAN}

Word of mouth adalah tindakan konsumen memberikan informasi kepada konsumen lain dari seseorang kepada orang lain (antarpribadi) non komersial baik merek, produk maupun jasa. ${ }^{1}$

Kotler berpendapat, Word of Mouth Communication adalah komunikasi pribadi tentang sebuah produk antara pembeli sasaran dan tetangga, teman, anggota keluarga, serta rekannya. ${ }^{2}$

Word Of Mouth ada 2 yaitu, word of mouth positif dan word of mouth negatif. Apabila konsumen menyebarkan opininya mengenai kebaikan produk maka disebut sebagai positif WOM, tetapi bila konsumen menyebarluaskan opininya mengenai keburukan produk maka disebut sebagai negatif WOM. ${ }^{3}$

Dari penjelasan diatas dapat disimpulkan bahwa Word of mouth ada 2 yaitu, word of mouth positif dan word of mouth negatif. Apabila konsumen menyebarkan opininya mengenai kebaikan produk maka disebut sebagai positif WOM, tetapi bila konsumen menyebarluaskan opininya mengenai keburukan produk maka disebut sebagai negatif WOM.

Menurut Jalilvand dalam Wijaya dan Paramita menerangkan bahwa WOM (Word of Mouth) berperan besar dalam pengambilan keputusan oleh konsumen dan dalam pembentukan pola perilaku konsumen. WOM dirasa lebih efektif karena informasinya yang lebih relibel. Jenis komunikasi dengan pesan non-commercial ini memiliki tingkat persuasif yang lebih tinggi dengan kepercayaan dan kredibilitas yang tinggi pula. Sebagian besar orang cenderung lebih percaya pada pemasaran dari mulut ke mulut dibanding metode promosi apapun sifatnya lebih formal. Orang yang menerima rekomendasi berdasarkan komunikasi dari mulut ke mulut cenderung lebih yakin bahwa sang pemberi rekomendasi berbicara jujur dan tidak ditunggangi motif tersembunyi. ${ }^{4}$

Dari pengertian di atas dapat disimpulkan bahwa Word of Mouth siswa adalah menyebarkan informasi dari melalui komunikasi dari mulut ke mulut antara siswa yang

\footnotetext{
${ }^{1}$ Ali Hasan, Marketing dari Mulut ke Mulut, Yogyakarta:Media Pressindo, hal. 32

${ }^{2}$ Kotler, Prinsip-Prinsip Pemasaran, Jakarta:erlangga, hal. 615

${ }^{3}$ Putriadhi Rahma Hananing, Analisis Pengaruh Kualitas Layanan Terhadap Implementasi Words Of

Mouth Pada lembaga Pendidikan English First Semarang. 2011. Tersedia di http://eprints.undip.ac.id/29312/1/Skripsi014.pdf di unduh pada tanggal.07 Oktober 2017

${ }^{4}$ Wijaya, Tommi, dan Paramita, Eristia L, Pengaruh Electronic Word Of Mouth (Ewom) Terhadap Keputusan Pembelian Kamera Dslr, 2014.
} 
satu dengan calon siswa, keluarga, kerabat, dan tetangga. Word of Mouth positif siswa adalah siswa menyebarkan informasi secara langsung sehingga memberikan gambaran informasi yang meyakinkan kepada calon siswa lainnya seperti kerabat, teman, dan tetangga bahwa di sekolah terdapat kompetensi guru yang sudah bagus. Word of mouth negatif siswa masih minim dalam menyebarkan informasi positif sehingga kurang mendorong orang lain untuk berminat di sekolah yang dituju, padahal peran Word of Mouth sangat penting agar konsumen tertarik dan mengkonsumsi jasa yang ditawarkan.

Word of Mouth bisa dipengaruhi oleh kompetensi guru yang mengajar selalu memberikan yang terbaik untuk siswa, yaitu dengan memberikan pelayanan yang memuaskan melalui kompetensi baik tenaga pendidik maupun tenaga kependidikan, sehingga diharapkan akan menciptakan kualitas layanan dimana akan berpengaruh terhadap Word of Mouth (WOM). ${ }^{5}$

Kompetensi guru merupakan seperangkat pengetahuan, keterampilan, dan perilaku yang harus dimiliki, dihayati, dikuasai, dan diaktualisasikan oleh Guru dalam melaksanakan tugas keprofesionalan. Berdasarkan Peraturan Pemerintah (PP) Nomor 18 Tahun 2007 tentang Guru, dinyatakan bahwasanya kompetensi yang harus dimiliki oleh Guru meliputi kompetensi pedagogik, kompetensi kerpibadian, kompetensi sosial, dan kompetensi professional yang diperoleh melalui pendidikan profesi. Kompetensi Guru tersebut bersifat menyeluruh dan merupakan satu kesatuan yang satu sama lain saling berhubungan dan saling mendukung. Kompetensi pedagogik yang dimaksud yakni kemampuan pemahaman tentang peserta didik secara mendalam dan penyelenggaraan pembelajaran yang mendidik. Pemahaman tentang peserta didik meliputi pemahaman tentang psikologi perkembangan anak. Sedangkan pembelajaran yang mendidik meliputi kemampuan merancang pembelajaran, mengimplementasikan pembelajaran, menilai proses dan hasil pembelajaran, dan melakukan perbaikan secara berkelanjutan. ${ }^{6}$

Kompetensi kepibadian Guru sering dianggap sebagai sosok yang memiliki kepribadian ideal. Oleh karena itu, pribadi guru sering dianggap sebagai model atau panutan (yang harus digugu dan ditiru). Sebagai seorang model guru harus memiliki kompetensi yang berhubungan dengan pengembangan kepribadian (personal competencies), diantaranya: (1) kemampuan yang berhubungan dengan pengalaman ajaran agama sesuai dengan keyakinan agama yang dianutnya, (2) kemampuan untuk

\footnotetext{
${ }^{5}$ Op. Cit Putriadhi Rahma Hananing, Analisis Pengaruh Kualitas Layanan Terhadap Implementasi Words Of Mouth Pada lembaga Pendidikan English First Semarang. 2011. Tersedia di http://eprints.undip.ac.id/29312/1/Skripsi014.pdf di unduh pada tanggal.07 Oktober 2017

${ }^{6}$ Nasrul, Profesi Etika dan Keguruan, Yogyakarta:Aswaja Pressindo, hal. 37-38.
} 
menghormati dan menghargai antar umat beragama, (3) kemampuan untuk berperilaku sesuai dengan norma, aturan, dan sistem nilai yang berlaku dimasyarakat, (4) mengembangkan sifat-sifat terpuji sebagai seorang guru misalnya sopan santun dan tata karma dan, (5) bersikap demokratis dan terbuka terhadap pembaruan dan kritik. Kepribadian merupakan organisasi faktor-faktor biologis, psikologis, dan sosiologis yang mendasari perilaku individu. Kepribadian mencakup kebiasaan-kebiasaan, sikap, dan lain-lain sifat khas dimiliki seseorang yang berkembang apabila orang tadi berhubungan dengan orang lain. ${ }^{7}$

Kompetensi sosial Kompetensi ini berhubungan dengan kemampuan guru sebagai anggota masyarakat dan sebagai makhluk sosial, meliputi: (1) kemampuan untuk berinteraksi dan berkomunikasi dengan teman sejawat untuk meningkatkan kemampuan professional, (2) kemampuan untuk mengenal dan memahami fungsi-fungsi setiap lembaga kemasyarakatan dan (3) kemampuan untuk menjalin kerja sama baik secara individual maupun secara kelompok. Dalam penjelasan pasal 10 ayat 1 ditegaskan bahwa data yang dimaksud dengan kompetensi sosial adalah kemampuan guru untuk berkomunikasi dengan bergaul secara efektif dengan peserta didik, sesama pendidikan, orang tua/wali peserta didik, dan masyarakat sekitar. Di dalam versi lain juga dikatakan bahwa kompetensi sosial merupakan kemampuan guru untuk memahami dirinya sebagai bagian yang tidak terpisahkan dari masyarakat dan mampu mengembangkan tugas sebagai anggota masyarakat dan warga Negara. ${ }^{8}$

Kompetensi professional adalah kompetensi atau kemampuan yang berhubungan dengan penyesuaian tugas-tugas keguruan. Oleh sebab itu, tingkat keprofesionalan seorang guru dapat dilihat dari kompetensi sebagai berikut: (1) kemampuan untuk menguasai landasan pendidikan, misalnya paham akan tujuan pendidikan yang harus dicapai baik tujuan nasional, instutusional, kurikuler, dan tujuan pembelajaran. (2) pemahaman dalam bidang psikologi pendidikan, misalnya paham tentang tahapan perkembangan siswa, paham tentang teori-teori belajar. (3) kemampuan dalam penguasaan materi pelajaran sesuai dengan bidang studi yang diajarkannya. (4) kemampuan dalam mengaplikasikan berbagai metodologi dan strategi pembelajaran. (5) kemampuan merancang dan memanfaatkan berbagai media dan sumber belajar. (6) kemampuan dalam melaksanakan evaluasi pembelajaran. (7) kemampuan dalam menyusun program pembelajaran. (8) kemampuan dalam melaksanakan unsur penunjang, 
misalnya administrasi sekolah, bimbingan dan penyuluhan dan (9) kemampuan dalam melaksanakan penelitian dan berpikir ilmiah untuk meningkatkan kinerja. Di dalam Undang-undang No. 14 tentang Guru dan Dosen dinyatakan bahwa Kompetensi professional adalah kemampuan penguasaan materi pembelajaran secara luas dan mendalam yang memungkinkan membimbing peserta didik memenuhi standar kompetensi yang ditetapkan dalam Standar Nasional Pendidikan. ${ }^{9}$

Dari penjelasan di atas dapat disimpulkan bahwa seorang guru harus mempunyai ke empat kompetensi guru yang ada dalam dirinya, kompetensi yang dimaksud adalah kompetensi pedaogik, kompetensi kepribadian, kompetensi sosial dan kompetensi professional. Dan guru harus mempunyai akal yang cerdas guna untuk menyampaikan suatu ilmunya yang di bagikan atau yang diajarkannya kepada siswa nya. Agar siswanya dapat menimba ilmu yang bermanfaat bagi dirinya.

Di Sekolah Menengah Atas Mummadiyah 1 Pekanbaru berdasarkan hasil observasi guru sudah memiliki kompetensi pedagogik meliputi pemahaman terhadap peserta didik, kompetensi kepribadian mengembangkan sifat-sifat terpuji sebagai seorang guru, kompetensi sosial kemampuan guru untuk berkomunikasi dengan bergaul secara efektif dengan peserta didik, dan kompetensi professional kemapuan penguasaan materi pembelajaran secara luas dan mendalam memungkinkan membimbing peserta didik, namun siswa masih banyak yang berkomunikasi negatif tentang Kompetensi Guru khususnya Guru di Rumpun IPS. Hal itu terlihat dari gejala-gejala sebagai berikut:

1. Masih ada sebagian siswa yang menceritakan hal-hal negatif tentang cara guru mengajar.

2. Masih ada sebagian siswa tidak menyarankan orang lain untuk bergabung ke Sekolah Menengah Atas Muhammadiyah 1 Pekanbaru.

3. Masih ada sebagian siswa tidak setuju kerabatnya belajar di Sekolah Menengah Atas Muhammadiyah 1 Pekanbaru

Berdasarkan gejala-gejala diatas, penulis tertarik untuk melakukan penelitian tentang Pengaruh Kompetensi Guru Rumpun IPS Terhadap Word Of Mouth Positif Siswa di Sekolah Menengah Atas Muhammadiyah 1 Pekanbaru dengan tujuan untuk mengetahui pengaruh kompetensi guru rumpun IPS tersebut terhadap word of mouth positif siswa di Sekolah Menengah Atas Muhammadiyah 1 Pekanbaru.

${ }^{9}$ Ibid, hal. 48-49 
Adapun rumusan masalah yang dibangun untuk penelitian ini adalah apakah ada pengaruh yang signifikan antara kompetensi guru rumpun IPS terhadap word of mouth positif siswa di Sekolah Menengah Atas Muhammadiyah 1 Pekanbaru.

\section{METODE PENELITIAN}

Desain penelitian yang digunakan dalam penelitian ini adalah survey. Survey yang digunakan untuk mendapatkan data dari tempat tertentu, tetapi peneliti melakukan perlakuan dalam pengumpulan data, misalnya dengan mengedarkan kuesioner. $^{10}$

Penelitian ini dapat digolongkan sebagai penelitian lapangan (Field Research) dengan pendekatan kuantitatif, yakni suatu proses menemukan pengetahuan yang menggunakan data berupa angket sebagai alat untuk menemukan keterangan mengenai apa yang ingin diketahui.

Makna lain pendekatan kuantitatif, yakni metode penelitian yang berlandaskan pada filsafat positivisme, digunakan untuk meneliti pada populasi atau sampel tertentu, pengumpulan data menggunakan instrument penelitian, analisis data bersifat kuantitatif atau statistik dengan tujuan untuk menguji hipotesis yang telah ditetapkan. $^{11}$

Sesuai permasalahan yang diangkat pada penelitian ini adalah permasalahan asosiatif, yaitu suatu pertanyaan penelitian yang bersifat menghubungkan dua variabel atau lebih. Hubungan variabel dalam penelitian adalah hubungan kausal, yaitu hubungan yang bersifat sebab akibat. Ada variabel independent (variabel yang mempengaruhi) dan variabel dependent (dipengaruhi). Variabel independent dalam penelitian ini adalah kompetensi guru (X), serta word of mouth (Y) sebagai variabel dependent.

Penelitian ini dilaksanakan di bulan September 2017 di Sekolah Menengah Atas Muhammadiyah 1 Pekanbaru.

Subjek penelitian ini adalah seluruh siswa kelas XI Jurusan IPS di Sekolah Menengah Atas Muhammadiyah 1 Pekanbaru, sedangkan objek penelitian ini adalah (X) kompetensi dengan sub variabel $\mathrm{X}_{1}$ (kompetensi pedagogik), $\mathrm{X}_{2}$ (kompetensi kepribadian), $\mathrm{X}_{3}$ (kompetensi sosial), $\mathrm{X}_{4}$ (kompetensi professional) terhadap (Y) word

\footnotetext{
${ }^{10}$ Sugiyono, Metode Penelitian Pendidikan Pendekatan Kuantitatif, kualitatif, dan R\&D, Bandung:alfabeta, 2016, hal. 6

${ }^{11}$ Ibid, hal. 8
} 
of mouth positif siswa di kelas XI di Sekolah Menengah Atas Muhammadiyah 1 Pekanbaru.

Populasi adalah wilayah generalisasi: obyek/subyek yang mempunyai kualitas dan karakteristik tertentu yang ditetapkan oleh peneliti untuk dipelajari dan kemudian ditarik kesimpulannya. ${ }^{12}$ Populasi dalam penelitian ini adalah seluruh siswa-siswi Sekolah Menengah Atas Muhammadiyah 1 Pekanbaru yang berjumlah 660 siswa.

Sampel merupakan adalah bagian dari jumlah dan karakteristik yang dimiliki oleh populasi. Bila populasi besar, dan peneliti tidak mungkin mempelajari semua yang ada di populasi, maka peneliti dapat menggunakan sampel yang diambil dari populasi itu. ${ }^{13}$ Penulis mengambil sampel siswa kelas XI IPS yang berjumlah 82 orang. Teknik pengambilan sampel yang digunakan penulis adalah dengan menggunakan "Stratified Purposive Random Samplingi”.

Untuk mendapatkan data yang diperlukan dalam penelitian ini, penulis mengambil data primer. Adapun data primer adalah data yang diperoleh dari lapangan dengan teknik sebagai berikut:

\section{a. Angket}

Angket (kuesioner) yaitu teknik pengambilan data yang dilakukan dengan cara memberi seperangkat pertanyaan atau pertanyaan tertulis kepada responden untuk dijawabnya. ${ }^{14}$ Untuk memperoleh data, angket disebarkan kepada siswa untuk diisi dan kemudian hasilnya dianalisis. Analisis ini ditujukan untuk mencari data yang berhubungan dengan pelaksanaan kompetensi guru dan word of mouth positif. Penulis menggunakan metode angket yang disusun dengan menggunakan angket model skala Likert. Skala Likert ada lima interval, yaitu:

$\begin{array}{ll}\text { Selalu } & \text { : skor } 5 \\ \text { Sering } & \text { : skor } 4 \\ \text { Kadang- kadang } & \text { : skor } 3 \\ \text { Jarang } & \text { :skor } 2 \\ \text { Tidak pernah } & \text { :skor } 15\end{array}$

\section{b. Dokumentasi}

\footnotetext{
${ }^{12}$ Sugiyono, Statistik untuk Penelitian, Bandung:alfabeta, 2014. Hal. 61

${ }^{13}$ Ibid, Hal. 62

${ }^{14}$ Sugiyono, Op.Cit, hal. 142

${ }^{15}$ Ridwan, Skala Pengukuran Variabel-Variabel Penelitian, Bandung:Alfabeta, 2013, hal. 13
} 
Teknik ini digunakan untuk mengungkap data yang mendukung penelitian ini, yaitu dokumen yang berkaitan dengan data sekolah. Misalnya sejarah sekolah, visi dan misi sekolah, kondisi guru, kondisi siswa, dan sarana prasarana sekolah.

Penulis menggunakan Instrument penelitian untuk memperoleh, mengolah dan menginterpretasikan informasi yang diperoleh dari para responden yang dilakukan dengan menggunakan pola ukur yang sama. ${ }^{16}$ Instrument yang baik adalah isntrumen yang valid dan reliable. Oleh sebab itu, sebelum data penelitian dianalisa, penulis melakukan uji validitas dan reliabilitas.

Teknik analisis data dalam penelitian ini adalah menggunakan analisis kuantitatif. Tujuannya adalah untuk mengkaji variabel-variabel yang ada dalam penelitian. Data yang diperoleh untuk masing-masing variabel alternative jawaban dicari persentase jawabannya dengan rumus:

$$
\mathrm{P}=\frac{F}{N} \times 100 \%
$$

Keterangan:

$\mathrm{P}=$ angka persentase

$\mathrm{F}=$ frekuensi yang dicari

$\mathrm{N}=$ number of case (jumlah frekuensi/banyak individu). ${ }^{17}$

Hasil pengelolaan data, selanjutnya akan ditafsirkan kedalam klasifikasi sebagai berikut:

$$
\begin{array}{ll}
81 \%-100 \% & =\text { sangat baik } \\
61 \%-80 \% & =\text { baik } \\
41 \%-60 \% & =\text { cukup baik } \\
21 \%-40 \% & =\text { tidak baik } \\
0 \%-20 \% & =\text { sangat tidak baik }
\end{array}
$$

Selanjutya data yang diperoleh berupa data ordinal dari angket dirubah menjadi data interval dengan menggunakan rumus sebagai berikut:

$$
\mathrm{T}_{\mathrm{i}=50+10} \frac{(x i-x)}{S D}
$$

Keterangan $\mathrm{Xi}=$ variabel data ordinal

$$
\begin{aligned}
& \mathrm{X}=\text { mean (rata-rata) } \\
& \mathrm{SD}=\text { standar deviasi. }^{19}
\end{aligned}
$$

\footnotetext{
${ }^{16}$ Syofian Siregar, Statistik Parametrik untuk Penelitian Kuantitatif, Jakarta:PT Bumi Aksara, 2014, hal. 75

${ }^{17}$ Anas Sudijono, Pengantar Statistik Pendidikan, Jakarta:Raja Grafindo Persada, 2010, hal. 43

${ }^{18}$ Ridwan, Op. Cit, hal. 15
} 
Uji normalitas selanjutnya digunakan untuk menentukan data yang telah dikumpulkan berdistribusi normal. Uji normalitas dalam penelitian ini dilakukan bantuan program SPSS 20.0 For Windows. Teknik uji normalitas yang dapat digunakan dalam menguji distribusi normal data diantaranya probability plot dan kolmogorovmirnov. Pada penelitian ini untuk menguji apakah distribusi data normal atau tidak, dilakukan dengan metode uji kolmogrov-smirnov. Kaidah yang digunakan untuk mengetahui normal atau tidaknya sebaran data adalah jika $\mathrm{p}>$ 0,05 maka sebaran normal atau tidaknya sebaran data adalah jika $\mathrm{p}<0,05$ maka sebaran tidak normal. ${ }^{20}$

Uji lineritas kemudian digunakan untuk mengetahui kelinearitas data sebagai persyaratan data dalam pengujian statistik lebih lanjut. Hipotesis yang diuji adalah:

Ho : Distribusi data yang diteliti tidak mengikuti bentuk linear

Ha : Distribusi data yang diteliti mengikuti bentuk linear

Dari pengambilan keputusan adalah:

Jika probabilitas $>0.05=$ Ho diterima

Jika probabilitas $>0.05=$ Ho ditolak

Teknik analisis data menggunakan analisis kuantitatif. Analisis data yang digunakan untuk mengetahui pengaruh variabel (X) kompetensi dengan sub variabel $\mathrm{X}_{1}$ (kompetensi pedagogik), $\mathrm{X}_{2}$ (kompetensi kepribadian), $\mathrm{X}_{3}$ (kompetensi sosial), $\mathrm{X}_{4}$ (kompetensi professional) terhadap (Y) word of mouth positif siswa. Teknik korelasi yang digunakan adalah dengan analisis regresi linear berganda.

Untuk mengetahui ada tidaknya pengaruh kompetensi guru terhadap word of mouth positif siswa, maka data yang dianalisis menggunakan pendekatan kuantitatif dengan menggunakan teknik analisis regresi linear berganda. ${ }^{21}$

$$
\mathrm{Y}=\alpha+b_{1} \mathrm{X}_{1}+\mathrm{b}_{2} \mathrm{X}_{2}+\mathrm{b}_{3} \mathrm{X}_{3}+\mathrm{b}_{4} \mathrm{X}_{4}
$$

Keterangan:

$\mathrm{Y}=$ Variabel dependent (variabel kriterium dipengaruhi).

$\alpha \quad=$ Konstanta

$\mathrm{B}_{1} \mathrm{~b}_{2} \mathrm{~b}_{3} \mathrm{~b}_{4}=$ Koefisien regresi predictor $\mathrm{X}_{1} \mathrm{X}_{2} \mathrm{X}_{3} \mathrm{X}_{4}$

$\mathrm{X}=$ Variabel independent (variabel prediktor)

$\mathrm{X}_{1} \quad=$ Kompetensi Pedagogik

\footnotetext{
${ }^{19}$ Hartono, Statistik untuk Pendidikan, Yogyakarta:Pustaka Belajar, 2010, hal. 160

${ }^{20}$ Imam Ghozali, Aplikasi Analisis Multivariat dengan Program SPSS, Semarang:Badan Penerbit Universitas Diponegoro, 2006. Hal. 112

${ }^{21}$ Hartono, Statistik untuk Penelitian, Pekanbaru: Pustaka Belajar, 2011, hal. 160
} 
$\mathrm{X}_{2} \quad=$ Kompetensi Kepribadian

$\mathrm{X}_{3} \quad=$ Kompetensi Sosial

$\mathrm{X}_{4} \quad=$ Kompetensi Professional

Jadi, pengujian hipotesis yang menggunakan analisis regresi ganda dengan melihat Fhitung dan Ftabel lebih besar dari Ftabel maka $H_{a}$ diterima dan $H_{o}$ ditolak.

Pengujian selanjutnya adalah dengan menguji $\mathrm{r}$ (pengujian hipotesis) yaitu membandingkan rt (tabel) untuk mengetahui taraf signifikan hipotesis dengan ketentuan:

a. Jika $r_{o} \geq r_{t}$, maka Ha diterima, Ho ditolak.

b. Jika $r_{o} \leq r_{t}$, maka Ha diterima, Ho ditolak.

Uji secara simultan (Uji F) digunakan untuk mengetahui seberapa besar variabel independent (X) secara bersama-sama berpengaruh terhadap variabel dependen (Y). analisis Uji $\mathrm{F}$ dilakukan dengan membandingkan $\mathrm{F}$ hitung dan $\mathrm{F}$ tabel. Sebelum membandingkan nilai $\mathrm{F}$, harus ditentukan tingkat kepercayaan (1$\alpha$ ) dan derajat kebebasan (degree of freedom) $=\mathrm{n}-(\mathrm{k}-1)$ agar dapat ditentukan nilai kritisnya. Adapun nilai Alpha yang digunakan dalam penelitian ini adalah sebesar 0,05. Dimana kriteria pengambilan keputusan yang digunakan adalah sebagai berikut:

a. Apabila $F_{\text {hitung }}>F_{\text {tabel }}$ atau Sig $<\alpha$, maka:

Ho ditolak, Ha diterima, artinya kompetensi pedagogik, kompetensi kepribadian, kompetensi sosial, kompetensi professional. Terhadap word of mouth positif siswa di Sekolah Menengah Atas Muhammadiyah 1 Pekanbaru mempunyai pengaruh yang signifikan secara bersama-sama terhadap Variabel terikat yaitu word of mouth positif siswa.

b. Apabila $F_{\text {hitung }}>F_{\text {tabel }}$ atau $\operatorname{Sig}<\alpha$, maka:

Ho ditolak, Ha diterima, artinya kompetensi pedagogik, kompetensi kepribadian, kompetensi sosial, kompetensi professional. Terhadap word of mouth positif siswa di Sekolah Menengah Atas Muhammadiyah 1 Pekanbaru tidak mempunyai pengaruh yang signifikan secara bersama-sama terhadap Variabel terikat yaitu word of mouth positif siswa.

Selanjutnya besarnya sumbangan variabel $\mathrm{X}$ terhadap Variabel $\mathrm{Y}$ dihitung dengan rumus:

$$
\mathrm{KP}=\mathrm{r}^{2} \times 100 \%
$$


Keterangan : KP = Nilai Koefisien Diterminan

$\mathrm{R}^{2}=$ Nilai Koefisien Korelasi. ${ }^{22}$

\section{HASIL DAN PEMBAHASAN}

\section{A. Analisis Data}

\section{1) Deskripsi Data Hasil Penelitian}

Hasil penelitian lapangan tentang pengaruh kompetensi guru rumpun IPS terhadap word of mouth positif siswa di SMA Muhammadiyah 1 Pekanbaru setelah dilakukan skoring dan diolah dengan statistical package social science (SPSS) 21.0 for windows, diperoleh gambaran seperti yang disajikan dalam tabel dibawah.

TABEL I.

DESKRIPSI DATA HASIL PENELITIAN

Descriptive Statistics

\begin{tabular}{|l|r|r|r|r|r|}
\hline & \multicolumn{1}{|c|}{ N } & Minimum & Maximum & Mean & Std. Deviation \\
\hline KGR & 82 & 49.0 & 92.0 & 72.793 & 10.7803 \\
WMP & 82 & 17.0 & 30.0 & 22.841 & 3.3974 \\
Valid N (listwise) & 82 & & & & \\
& & & & & \\
\hline
\end{tabular}

Sumber: Data Olahan, 2017

Deskripsi data ini memberikan gambaran penting mengenai keadaan distribusi skor angket tentang kompetensi guru rumpun IPS (KGR)danword of mouth positif siswa (WMP) pada kelompok subjek yang dikenai pengukuran dan berfungsi sebagai sumber informasi mengenai keadaan subjek pada aspek atau variabel yang teliti.

\section{2) Perubahan Data Ordinal ke Interval}

Data tentang kompetensi guru rumpun IPS dan word of mouth positif siswa yang didapat dari angket merupakan data ordinal, yang selanjutnya akan diubah menjadi data interval, agar data dapat dianalisis dengan regresi berganda. Adapun untuk mengubah data ordinal ke data interval dengan menggunakan rumus sebagai berikut:

$$
\mathrm{Ti}=50+10\left(\frac{\mathrm{Xi}-\overline{\overline{\mathrm{X}}}}{\mathrm{SD}}\right)
$$

\footnotetext{
${ }^{22}$ Riduwan dan Sunarto, Pengantar Statistik untuk Penelitian Pendidikan Sosial Ekonomi Komunikasi dan Bisnis, Bandung:IKAPI, 2011, hal. 81
} 
Berdasarkan rumus tersebut diperoleh data interval dari masing-masing variabel. Data selengkapnya dapat dilihat pada lampiran

\section{3) Uji Normalitas}

Uji normalitas data bertujuan untuk mengetahui apakah data berdistribusi normal.Uji normalitas dilakukan pada masing-masing variabel. Kaidah yang digunakan untuk mengetahui normal atau tidaknya sebaran data adalah jika $\mathrm{p}>$ 0,05 maka sebaran normal atau tidaknya sebaran data adalah jika $\mathrm{p}<0,05$ maka sebaran tidak normal. Berdasarkan perhitungan data yang dilakukan dengan one sample kolmogorof-smirnov test maka didapat data hasil yang tergambar pada tabel berikut:

TABEL II.

\section{UJI NORMALITAS DATA}

\section{One-Sample Kolmogorov-Smirnov Test}

\begin{tabular}{|ll|r|r|}
\hline & & \multicolumn{1}{|c|}{ KGR } & \multicolumn{1}{l|}{ WMP } \\
\hline N & & 82 & 82 \\
& Mean & 72.793 & 22.841 \\
& Std. Deviation & 10.7803 & 3.3974 \\
& Absolute & .130 & .128 \\
Most Extreme Differences & Positive & .098 & .106 \\
& Negative & -.130 & -.128 \\
Kolmogorov-Smirnov Z & & 1.177 & 1.162 \\
Asymp. Sig. (2-tailed) & & .125 & .134 \\
\hline
\end{tabular}

a. Test distribution is Normal.

b. Calculated from data.

Sumber: Data Olahan, 2017

Berdasarkan tabel di atas tersebut diperoleh nilai signifikansi pada tabel one sample kolmogorof-smirnov test pada variabel kompetensi guru rumpun IPS (KGRdiperoleh nilai $p=0,125$, variabel word of mouth positifsiswa (WMP) diperoleh nilai $p=0,134$. Jadi, nilai p (Asymp. Sig. (2-tailed)) lebih besar dari alpha 0,05 ( $p>$ $0,05)$. Keterangan yang dapat diambil bahwa data tersebut adalah berdistribusi normal dan layak dianalisis lebih lanjut. 


\section{4) Uji Multikolinearitas}

Model regresi ganda yang baik seharusnya tidak terjadi korelasi diantara variabel bebasnya. Pedoman suatu model regresi yang bebas multikolinearitas adalah nilai besaran Variance Inflation Factor (VIF)dan Tolerance, jika VIF $<10$ dan mempunyai angka Tolerance $>0,1$. Hasil pengujian multikolinearitas dengan menggunakan SPSS menunjukkan informasi yang termuat pada table berkut:

TABEL III.

NILAI VIF DAN TOLERANCE

Coefficients $^{\mathrm{a}}$

\begin{tabular}{|c|c|c|c|}
\hline \multirow{2}{*}{\multicolumn{2}{|c|}{ Model }} & \multicolumn{2}{|c|}{ Collinearity Statistics } \\
\hline & & $\begin{array}{c}\text { Toleranc } \\
\mathrm{e}\end{array}$ & VIF \\
\hline \multirow{5}{*}{1} & (Constant) & & \\
\hline & $\mathrm{X} 1$ & .133 & 7.521 \\
\hline & $\mathrm{X} 2$ & .204 & 4.892 \\
\hline & X3 & .579 & 1.726 \\
\hline & $\mathrm{X} 4$ & .194 & 5.166 \\
\hline
\end{tabular}

a. Dependent Variable: WMP

Sumber: Data Olahan, 2017

Berdasarkan tabel di atas dapat dilihat seluruh sub variabel (Kompetensi pedagogik, kompetensi kepribadian, kompetensi sosial dan kompetensi professional )memliki VIF $<10$ dan nilai toleransi $>$ 0,1. Jadi, dapat disimpulkan bahwa model regresi bebas dari pengaruh multikolinearitas.

\section{5) Uji Regresi Berganda}

Pengujian hipotesis penelitian dilakukan dengan menggunakan analisis regresi berganda, karena dalam modelnya memasukkan dua variabel independen dan satu variabel dependen.Analisis ini digunakan untuk mengetahui pengaruh variabel independen dengan variabel dependen, apakah variabel independen berhubungan positif atau negatif juga apakah nilai variabel telah signifikan atau tidak signifikan dan untuk memprediksi nilai dari variabel dependen apabila nilai variabel 
mengalami kenaikan atau penurunan. Di bawah ini adalah hasil pengujian data dengan menggunakan regresi berganda sebagai berikut:

TABEL IV. MODEL PERSAMAAN REGRESI

Coefficients $^{\mathrm{a}}$

\begin{tabular}{|c|r|r|r|r|r|}
\hline Model & \multicolumn{2}{|c|}{$\begin{array}{c}\text { Unstandardized } \\
\text { Coefficients }\end{array}$} & $\begin{array}{c}\text { Standardize } \\
d \\
\text { Coefficients }\end{array}$ & \multicolumn{1}{c|}{$\mathrm{t}$} & Sig. \\
\cline { 2 - 4 } & \multicolumn{1}{|c|}{ B } & Std. Error & \multicolumn{1}{|c|}{ Beta } & & \\
\hline (Constant) & .019 & .826 & & .023 & .982 \\
X1 & .449 & .098 & .383 & 4.574 & .000 \\
1 X2 & .237 & .066 & .241 & 3.572 & .001 \\
X3 & .374 & .060 & .251 & 6.246 & .000 \\
X4 & .206 & .070 & .204 & 2.932 & .004 \\
\hline
\end{tabular}

a. Dependent Variable: WMP

Sumber: Data Olahan, 2017

Berdasarkan tabeldi atas dapat dihasilkan sebuah persamaan regresi yaitu:

$Y 1=0,019+0,449 X_{1}+0,237 X_{2}+0,3747 X_{3}+0,206 X_{4}$

Berdasarkan persamaan regresi tersebut menunjukkan koefisien regresi dari $b_{1}, b_{2}$, $b_{3}, b_{4}$,bernilai. Hal ini menunjukkan apabila terjadi peningkatan pada sub variabel bebas (kompetensi pedagogik, kompetensi kepribadian, kompetensi sosial, dan kompetensi professional) maka akanmenimbulkan peningkatan pada variabel terikatnya, dengan penjelasan sebagai berikut:

a. Nilai konstanta sebesar 0,019bermakna bahwa tanpa adanya perubahan (konstan) pada sub variabel kompetensi guru rumpun IPS yang meliputi kompetensi pedagogik, kompetensi kepribadian, kompetensi sosial, dan kompetensi professional maka word of mouth positifsiswa tetap memiliki nilai sebesar 0,019. Kemungkinan dari konstannya nilai word of mouth positifsiswa ini adalah dikarenakan adanya faktor- 
faktor lain di luar faktor kompetensi guru rumpun IPS yang meliputi kompetensi pedagogik, kompetensi kepribadian, kompetensi sosial, dan kompetensi professional

b. Nilai koefisien regresi sub variabel kompetensi guru rumpun ips kompetensi pedagogik $\left(\mathrm{X}_{1}\right)$ sebesar 0,449 bermakna setiap peningkatan sebesar satu satuan pada variabel kompetensi guru rumpun IPS maka word of mouth positif siswa akan meningkat sebesar 0,449 dengan asumsi variabel kompetensi guru rumpun IPS yang meliputi kompetensi pedagogik, kompetensi kepribadian, kompetensi sosial, dan kompetensi profesional adalah konstan.

c. Nilai koefisien regresi variabel kompetensi guru rumpun IPS kompetensi kepribadian $\left(\mathrm{X}_{2}\right)$ sebesar 0,237 bermakna setiap peningkatan sebesar satu satuan pada variabel kompetensi guru rumpun IPS kompetensi kepribadian maka word of mouth positif siswa akan meningkat sebesar 0,237 dengan asumsi variabel kompetensi guru rumpun IPS yang meliputi kompetensi pedagogik, kompetensi kepribadian, kompetensi sosial, dan kompetensi profesional adalah konstan.

d. Nilai koefisien regresi variabel kompetensi guru rumpun IPS kompetensi sosial $\left(\mathrm{X}_{3}\right)$ sebesar 0,374 bermakna setiap peningkatan sebesar satu satuan pada variabel kompetensi guru rumpun IPS kompetensi sosial maka word of mouth positif siswa akan meningkat sebesar 0,374 dengan asumsi variabel kompetensi guru rumpun IPS yang meliputi kompetensi pedagogik, kompetensi kepribadian, kompetensi sosial, dan kompetensi profesional adalah konstan.

e. Nilai koefisien regresi variabel kompetensi guru rumpun IPS kompetensi profesional guru rumpun IPS $\left(\mathrm{X}_{4}\right)$ sebesar 0,206 bermakna setiap peningkatan sebesar satu satuan pada variabel kompetensi guru rumpun IPS kompetensi professional dan kompetensi sosial guru rumpun IPS maka word of mouth positif siswa akan meningkat sebesar 0,206 dengan asumsi variabel kompetensi guru rumpun IPS yang meliputi kompetensi pedagogik, kompetensi kepribadian, kompetensi sosial, dan kompetensi professional adalah konstan.

\section{6) Uji Hipotesis}

Hipotesis yang diuji adalah sebagai berikut

Ha :Ada pengaruh yang signifikan antara kompetensi guru rumpun IPS terhadap word of mouth positif siswa Sekolah Menengah Atas Muhammadiyah 1 pekanbaru. 
Pengujian hipotesis yang dilakukan dengan simultan atau Uji F. Uji F dilakukan untuk melihat keberartian pengaruh variabel independen secara simultan terhadap variabel dependen atau sering disebut uji kelinieran persamaan regresi.

Pengambilan keputusan:

Ho diterima jika $\mathrm{F}$ hitung $<\mathrm{F}$ tabel atau sig $>5 \%$.

Ha diterima jika Fhitung $>\mathrm{F}$ tabel dan sig $<5 \%$.

TABEL V.

HASIL ANALISIS REGRESI SECARA SIMULTAN

ANOVA $^{\mathrm{a}}$

\begin{tabular}{|rr|r|r|r|r|r|}
\hline \multicolumn{2}{|l|}{ Model } & \multicolumn{1}{|c|}{$\begin{array}{c}\text { Sum of } \\
\text { Squares }\end{array}$} & df & Mean Square & $\mathrm{F}$ & Sig. \\
\hline \multirow{3}{*}{$1 \quad$ Regression } & 867.733 & 4 & 216.933 & 248.547 & $.000^{\circ}$ \\
& Residual & 67.206 & 77 & .873 & & \\
& Total & 934.939 & 81 & & & \\
\hline
\end{tabular}

a. Dependent Variable: WMP

b. Predictors: (Constant), X4, X3, X2, X1

Berdasarkan tabel Anova diperoleh nilai $\mathrm{F}=248 ., 547>2,490$ (nilai $\mathrm{F}$ tabel $=$ $2,490)$ dan sig $=0,000<5 \%$ ini berarti variabel independen kompetensi guru rumpun IPS secara simultan benar-benar mempunyai pengaruh signifikan terhadap variabel dependen word of mouth positif siswa, dengan kata lain variabel-variabel independen kompetensi guru rumpun IPS siswa mampu mempengaruhi besarnya variabel dependen word of mouth positif siswa.

Penelitian ini juga meneliti secara parsial Kompetensi Guru (X) dengan sub variabel : kompetensi pedagogik $\left(\mathrm{X}_{1}\right)$, kompetensi kepribadian $\left(\mathrm{X}_{2}\right)$, kepribadian sosial $\left(\mathrm{X}_{3}\right)$, kepribadian professional $\left(\mathrm{X}_{4}\right)$.

Hasilnya adalah sebagai berikut :

a. Pengaruh kompetensi pedagogik guru rumpun IPS terhadap word of mouth positif siswa. Hipotesa nya adalah :

Berdasarkan tabel IV.57 diperoleh nilai t hitung sebesar 4,574dengan signifikansi 0,000 , dengan tingkat kepercayaan $=95 \%$ atau $(\alpha)=0,05$ dengan 
derajat kebebasan $(\mathrm{df})=\mathrm{n}-\mathrm{k}-1=30-4-1=25$, serta pengujian dua sisi diperoleh dari nilai $\mathrm{t}_{0,05}=1,991$

Interpretasi dilakukan dengan cara

Ho diterima apabilat $\mathbf{t}_{\text {hitung }}<\mathbf{t}_{\text {tabela }}$ atau sig $\geq 5 \%$

Ha diterima apabila $t_{\text {hitung }}>t_{\text {tabel }}$ atau sig $<5 \%$.

Hasil pengujian statistik dengan SPSS pada variabel word of mouth positif diperoleh nilai $t_{\text {hitung }}=4,574$ sehingga $t_{\text {hitung }}=4,574>1,991=t_{\text {tabel }}$, dan $\operatorname{sig}=$ $0,000<5 \%$, jadi Ha diterima dan Ho ditolak. Ini berarti variabel kompetensi guru rumpun IPS kompetensi pedagogik guru rumpun IPS secara statistikmempengaruhi secara signifikan terhadap variabel dependen word of mouth positif siswa.

\section{TABEL VI}

KOEFISIEN DETERMINASI VARIABEL X1 TERHADAP Y

Measures of Association

\begin{tabular}{|l|r|r|r|r|}
\hline & \multicolumn{1}{|c|}{$\mathrm{R}$} & \multicolumn{1}{c|}{ R Squared } & Eta & Eta Squared \\
\hline $\mathrm{WMP}^{*} \mathrm{X} 1$ & .913 & .834 & .951 & .904 \\
\hline
\end{tabular}

Sumber: Data Olahan, 2017

Berdasarkan tabel di atas diperoleh nilai $R$ Square $=0,834=83,4 \%$ ini berarti variabel bebas kompetensi pedagogik guru rumpun IPSmempengaruhi variabel dependen word of mouth positifsebesar $83.4 \%$ (1) dan sisanya dipengaruhi oleh variabel lain yang tidak masuk dalam penelitian ini.

b. Pengaruh kompetensi kepribadian guru rumpun IPS terhadap word of mouth positif siswa. Hipotesa nya adalah :

Berdasarkan tabel IV.57 diperoleh nilai t hitung sebesar 3,572 dengan signifikansi 0,001 , dengan tingkat kepercayaan $=95 \%$ atau $(\alpha)=0,05$ dengan derajat kebebasan $(\mathrm{df})=\mathrm{n}-\mathrm{k}-1=30-4-1=25$, serta pengujian dua sisi diperoleh dari nilai $\mathrm{t}_{0,05}=1,991$

Interpretasi dilakukan dengan cara

Ho diterima apabila $\mathrm{t}_{\text {hitung }}<\mathrm{t}_{\text {tabel }}$ atau $\operatorname{sig} \geq 5 \%$

Ha diterima apabila $t_{\text {hitung }}>t_{\text {tabel }}$ atau sig $<5 \%$.

Hasil pengujian statistik dengan SPSS pada variabel word of mouth positif diperoleh nilai $t_{\text {hitung }}=3,572$ sehingga $t_{\text {hitung }}=3,572>1,991=t_{\text {tabel }}$, dan $\operatorname{sig}=$ 
0,001< 5\%,jadi Ha diterima dan Ho ditolak. Ini berarti variabel kompetensi kepribadian guru rumpun IPS secara statistikmempengaruhi secara signifikan terhadap variabel dependen word of mouth positif siswa

TABEL VII.

KOEFISIEN DETERMINASI VARIABEL X2 TERHADAP Y

Measures of Association

\begin{tabular}{|l|r|r|r|r|}
\hline & $\mathrm{R}$ & R Squared & \multicolumn{1}{|c|}{ Eta } & Eta Squared \\
\hline $\mathrm{WMP}^{*} \mathrm{X} 2$ & .888 & .788 & .910 & .828 \\
\hline
\end{tabular}

Sumber: Data Olahan, 2017

Berdasarkan tabel di atas diperoleh nilai $R$ Square $=0,788=78,8 \%$ ini berarti variabel bebas kompetensi kepribadian guru rumpun IPS mempengaruhi variabel dependen word of mouth positifsebesar $78,8 \%$ (2) dan sisanya dipengaruhi oleh variabel lain yang tidak masuk dalam penelitian ini.

c. Pengaruh kompetensi sosial guru rumpun IPS terhadap word of mouth positif siswa. Hipotesa nya adalah :

Berdasarkan tabel IV.57 diperoleh nilai t hitung sebesar 6,246 dengan signifikansi 0,000 , dengan tingkat kepercayaan $=95 \%$ atau $(\alpha)=0,05$ dengan derajat kebebasan $(\mathrm{df})=\mathrm{n}-\mathrm{k}-1=30-4-1=25$, serta pengujian dua sisi diperoleh dari nilai $\mathrm{t}_{0,05}=1,991$

Interpretasi dilakukan dengan cara

Ho diterima apabila $t_{\text {hitung }}<t_{\text {tabel }}$ atau $\operatorname{sig} \geq 5 \%$

Ha diterima apabila $\mathbf{t}_{\text {hitung }}>\mathbf{t}_{\text {tabel }}$ atau sig $<5 \%$.

Hasil pengujian statistik dengan SPSS pada variabel word mouth positif diperoleh nilai $t_{\text {hitung }}=6,246$ sehingga $t_{\text {hitung }}=6,246>1,991=t_{\text {tabel }}$, dan sig $=$ $0,000<5 \%$, jadi Ha diterima dan Ho ditolak. Ini berarti variabel kompetensi sosial guru rumpun IPS secara statistik mempengaruhi secara signifikan terhadap variabel dependen word of mouth positif siswa. 
TABEL VIII.

KOEFISIEN DETERMINASI VARIABEL X3 TERHADAP Y

Measures of Association

\begin{tabular}{|l|r|r|r|r|}
\hline & \multicolumn{1}{|c|}{$\mathrm{R}$} & \multicolumn{1}{|c|}{ R Squared } & \multicolumn{1}{|c|}{ Eta } & Eta Squared \\
\hline $\mathrm{WMP}^{*} \mathrm{X} 3$ & .726 & .527 & .791 & .625 \\
\hline
\end{tabular}

Sumber: Data Olahan, 2017

Berdasarkan tabel di atas diperoleh nilai $R$ Square $=0,527=52,7 \%$ ini berarti variabel bebas kompetensi sosial guru rumpun IPS mempengaruhi variabel dependen word of mouth positifsebesar $52,7 \%$ dan sisanya dipengaruhi oleh variabel lain yang tidak masuk dalam penelitian ini.

d. Pengaruh kompetensi professional guru rumpun IPS terhadap word of mouth positif siswa. Hipotesa nya adalah :

Berdasarkan tabel IV.57 diperoleh nilai t hitung sebesar 2,932 dengan signifikansi 0,004, dengan tingkat kepercayaan $=95 \%$ atau $(\alpha)=0,05$ dengan tingkat kepercayaan $=95 \%$ atau $(\alpha)=0,05$ dengan derajat kebebasan $(\mathrm{df})=\mathrm{n}-\mathrm{k}-1$ $=30-4-1=25$, serta pengujian dua sisi diperoleh dari nilai $t_{0,05}=1,991$

Interpretasi dilakukan dengan cara

Ho diterima apabila $t_{\text {hitung }}<\mathrm{t}_{\text {tabel }}$ atau $\operatorname{sig} \geq 5 \%$

Ha diterima apabila $t_{\text {hitung }}>t_{\text {tabel }}(4)$ atau sig $<5 \%$.

Hasil pengujian statistik dengan SPSS pada variabel word of mouth positif diperoleh nilai $t_{\text {hitung }}=2$,932sehingga $t_{\text {hitung }}=2,932>1,991=t_{\text {tabel }}$, dan $\operatorname{sig}=$ $0,004<5 \%$, jadi Ha diterima dan Ho ditolak.

\section{TABEL IX.}

KOEFISIEN DETERMINASI VARIABEL X4 TERHADAP Y

Measures of Association

\begin{tabular}{|l|r|r|r|r|}
\hline & \multicolumn{1}{|c|}{$\mathrm{R}$} & \multicolumn{1}{|c|}{ R Squared } & \multicolumn{1}{c|}{ Eta } & Eta Squared \\
\hline WMP * X4 & .893 & .797 & .964 & .930 \\
\hline
\end{tabular}

Sumber: Data Olahan, 2017

Berdasarkan tabel di atas diperoleh nilai $R$ Square $=0,797=79,7 \%$ ini berarti variabel bebas kompetensi guru rumpun IPS kompetensi professional 
mempengaruhi variabel dependen word ofmouth positifsebesar 79,7\% dan sisanya dipengaruhi oleh variabel lain yang tidak masuk dalam penelitian ini.

Ho: Tidak ada pengaruh yang signifikan antara kompetensi guru rumpun IPS terhadap word of mouth positif siswa Sekolah Menengah Atas Muhammadiyah 1 Pekanbaru.

\section{7) Koefisien Determinasi Ganda $\left(\mathbf{R}^{2}\right)$}

Koefisien determinan $\left(\mathrm{R}^{2}\right)$ adalah sebuah koefisien yang menunjukkan seberapa besar persentase variabel-variabel independen, semakin besar koefisien determinasinya, maka semakin baik variabel independen dalam menjelaskan variabel dependen.Dengan demikian regresi yang dihasilkan baik untuk mengistimasi nilai variabel dependen. Berikut disajikan hasil output SPSS dari analisis perhitungan koefisien determinan $\left(\mathrm{R}^{2}\right)$.

TABEL $X$.

KOEFISIEN DETERMINASI VARIABEL X1, X2, X3 dan X4 TERHADAP Y

Model Summary

\begin{tabular}{|l|r|r|r|r|}
\hline Model & \multicolumn{1}{|c|}{$\mathrm{R}$} & R Square & Adjusted R Square & $\begin{array}{c}\text { Std. Error of the } \\
\text { Estimate }\end{array}$ \\
\hline 1 & $.963^{\mathrm{a}}$ & .928 & .924 & .9342 \\
\hline
\end{tabular}

a. Predictors: (Constant), $\mathrm{X} 4, \mathrm{X} 3, \mathrm{X} 2, \mathrm{X} 1$

Berdasarkan tabel di atas diperoleh nilai $R$ Square $=0,928=92,8 \%$ ini berarti variabel bebas kompetensi guru IPS secara bersama-sama mempengaruhi variabel dependen word of mouth positifsebesar 92,8\% (5) dan sisanya dipengaruhi oleh variabel lain yang tidak masuk dalam penelitian ini.

\section{SIMPULAN DAN SARAN}

\section{Simpulan}

Berdasarkan penyajian dan analisis data yang telah dilakukan sebelumnya dalam penelitian di Sekolah Menengah Atas Muhammadiyah 1 Pekanbarumaka dapat disimpulkan sebagai berikut: 
1) Kompetensi guru rumpun IPS di Sekolah Menegah Ataas Muhammadiyah 1 Pekanbaru secara keseluruhan tergolong baik dengan rata-rata persentase 76,20\%.

2) Word of mouth positif siswa di Sekolah Menengah Atas Muhammadiyah 1 Pekanbaru keseluruhan tergolong baik dengan rata-rata persentase 76,14\%.

3) Hasil penelitian membuktikan bahwaada pengaruh kompetensi pedagogik guru rumpun IPS terhadap word of mouth positif siswa di Sekolah Menengah Atas Muhammadiyah 1 Pekanbaru besar pengaruh 83,4\%.

4) Hasil penelitian membuktikan bahwa ada pengaruh yang signifikan antarakompetensi kepribadian guru rumpun IPS terhadap word of mouth positif siswa di Sekolah Menengah Atas Muhammadiyah 1 Pekanbarubesar pengaruh $78,8 \%$.

5) Hasil penelitian membuktikan bahwa ada pengaruh yang signifikan antarakompetensi sosial guru rumpun IPS terhadap word of mouth positif siswadi Sekolah Menengah Atas Muhammadiyah 1 Pekanbaru besar pengaruh 52,7\%.

6) Hasil penelitian membuktikan bahwa ada pengaruh yang signifikan antarakompetensi professional guru rumpun IPS terhadap word of mouth positif siswa di Sekolah Menengah Atas Muhammadiyah 1 Pekanbaru besar pengaruh $79,7 \%$.

7) Hasil penelitian membuktikan bahwa ada pengaruh yang signifikan antarakompetensi guru secara simultan guru rumpun IPS terhadap word of mouth positif siswa di Sekolah Menengah Atas Muhammadiyah 1 Pekanbaru besar pengaruh $92,8 \%$.

\section{Saran}

Berdasarkan pembahasan dan kesimpulan yang telah diuraikan, maka dapat dikemukakan beberapa saran yaitu:

1) Berdasarkan jawaban angket siswa mengenai kompetensi pedagogik, dapat dilihat bahwa guru masih kurang memahami karakter siswa yang mengikuti proses belajar mengajar. Disarankan kepada guru agar lebih memahami karakter siswa yang mengikuti proses belajar mengajar.

2) Berdasarkan jawaban angket siswa mengenai kompetensi pedagogik, dapat dilihat bahwa guru masih kurang merancang dan melaksanakan evaluasi pembelajaran kepada siswanya. Disarankan kepada guru agar lebih maksimal merancang dan melaksanakan evaluasi pembelajaran kepada siswanya. 


\section{Daftar Pustaka}

Ali Hasan, Marketing dari Mulut ke Mulut, Yogyakarta:Media Pressindo, 2010.

Abdul Hadis dan Nurhayati B, Manajemen Mutu Pendidikan, Bandung:Alfabeta, 2012

Anas Sudijono, Pengantar Statistik Pendidikan, Jakarta:Raja Grafindo Persada, 2008.

Budi Trianto, Riset Modeling: Teori, Konsep, dan Prosedur Melakukan Penelitian serta Aplikasi Pengelolaan Data Penelitian dengan Program LISREL, Pekanbaru:AdhDhuha Institute, 2015.

Hartono, Analisis Item Instrument, Zanafa Publishing,2010.

Hartono, Statistik untuk Penelitian, Pekanbaru: Pustaka Belajar

Imam Ghozali, Aplikasi Analisis Multivariat dengan Program SPSS, Semarang:Badan Penerbit Universitas Diponegoro, 2006.

Jejen Musfah, Peningkatan Kompetensi Guru, Jakarta:Kencana, 2011.

Kotler, Prinsip-Prinsip Pemasaran, Jakarta:erlangga, 2008.

Nasrul, Profesi Etika Keguruan, Yogyakarta:Aswaja Pressindo, 2012.

Siti Suwadah Rimang, Meraih Predikat Guru dan Dosen Paripurna, Bandung:Alfabeta, 2011

Ridwan, Skala Pengukuran Variabel-Variabel Penelitian, Bandung:Alfabeta, 2010.

Ridwan, Skala Pengukuran Variabel-Variabel Penelitian, Bandung:Alfabeta, 2011.

Riduwan dan Sunarto, Pengantar Statistik untuk Penelitian Pendidikan Sosial Ekonomi

Komunikasi dan Bisnis, Bandung:IKAPI, 2011

Syofian Siregar, Statistik Parametrik untuk Penelitian Kuantitatif, Jakarta:PT Bumi Aksara, 2014.

Sugiyono, Statistika untuk Penelitia, Bandung:Alfabeta, 2013.

Sugiyono, Metode Penelitian Pendidikan Pendekatan Kuantitatif, kualitatif, dan $R \& D$, Bandung:alfabeta, 2009

Sugiyono, Metode Penelitian Kuantitatif Kualitatif dan $R \& D$, Bandung:Alfabeta, 2010

Suyanto dan Asep Jihad. Menjadi Guru Profesional, Jakarta:Erlangga, 2013.

Wijaya, Tommi, dan Paramita, Eristia L, Pengaruh Electronic Word Of Mouth (Ewom)

Terhadap Keputusan Pembelian Kamera Dslr, 2014.

http://eprints.undip.ac.id/29312/1/Skripsi014.pdf

http://manajemen.upy.ac.id/manajemen/wp-content/uploads/2016/12/Pengaruh-Iklan-dan-

Word-of-Mouth-terhadap-Niat-Konsumen-Studi-Kasus-pada-Fakultas-Ekonomi-

Universitas-PGRI-Yogyakarta.pdf 
EKLEKTIK :Jurnal Pendidikan Ekonomi dan Kewirausahaan Volume 2 Nomor 1 Tahun 2019 